Research Paper

\title{
A Real-World Data Study to Evaluate Treatment Patterns, Clinical Characteristics and Survival Outcomes for First- and Second-Line Treatment in Locally Advanced and Metastatic Urothelial Cancer Patients in Germany
}

\author{
Günter Niegisch ${ }^{*}$, Holger Gerullis ${ }^{*}$, Shih-Wen Lin ${ }^{3}$, Julie Pavlova ${ }^{4}$, Adam Gondos ${ }^{5}$, Anja Rudolph ${ }^{5}$, \\ Gabriele Haas ${ }^{5}$, Nora Hennies ${ }^{5}$ and Mario W. Kramer ${ }^{6 \varpi}$ \\ 1. Department of Urology, Medical Faculty, Heinrich-Heine-University Düsseldorf, Düsseldorf, Germany \\ 2. School of Medicine and Health Sciences, University Hospital for Urology, Carl von Ossietzky University Oldenburg, Germany \\ 3. Genentech, South San Francisco, CA, USA \\ 4. Roche, Basel, Switzerland \\ 5. Real World Insights, QuintilesIMS, Frankfurt, Germany \\ 6. Department of Urology, University Hospital Schleswig-Holstein, Lübeck, Germany \\ *Dr. Günter Niegisch and Dr. Holger Gerullis contributed equally to this manuscript \\ $\triangle$ Corresponding author: E-mail: Guenter.Niegisch@med.uni-duesseldorf.de \\ (c) Ivyspring International Publisher. This is an open access article distributed under the terms of the Creative Commons Attribution (CC BY-NC) license \\ (https:// creativecommons.org/licenses/by-nc/4.0/). See http://ivyspring.com/terms for full terms and conditions.
}

Received: 2017.10.04; Accepted: 2017.12.30; Published: 2018.03.29

\begin{abstract}
Background: Worldwide, urothelial carcinoma (UC) is a common cause of morbidity and mortality. In particular, the incidence of bladder cancer varies widely across Europe; Germany has the ninth highest international age-standardized incidence. For advanced UC or metastatic UC (mUC), platinum-based combination chemotherapy is the standard first-line (1L) treatment; however, there is wide heterogeneity of second-line $(2 \mathrm{~L})$ treatments, ranging from vinflunine in parts of Europe to taxanes and other agents elsewhere in Europe, in the United States and globally. Limited data exist on treatment patterns and outcomes in patients with advanced UC or mUC in the routine clinical setting in Germany. The objective of this study was to describe clinical characteristics, treatment patterns and subsequent outcomes in this setting.

Methods: This retrospective observational cohort analysis evaluated $1 \mathrm{~L}$ and $2 \mathrm{~L}$ treatment patterns and overall survival (OS) in patients aged $\geq 18$ years with advanced UC or mUC (T4b, N2-3 and/or MI) at office-based urology and academic as well as nonacademic urology clinics throughout Germany between 1 November 2009 and 2 June 2016. Data were obtained through the GermanOncology database and additional treatment centers using similar electronic case report forms.

Results: Among the 435 patients included in the analysis, 435 received $1 \mathrm{~L}$ treatment and 125 received $2 \mathrm{~L}$ treatment. Median age at start of $1 \mathrm{~L}$ treatment was 69 years, $75 \%$ of patients were male, $75 \%$ were current or ex-smokers, $15 \%$ had hemoglobin $<10 \mathrm{~g} / \mathrm{dL}$ and $44 \%$ had creatinine clearance $<60 \mathrm{~mL} / \mathrm{min} / 1.73$; proportions were similar with $2 \mathrm{~L}$ treatment. Cardiovascular disease was the most frequently reported comorbidity $(65 \%)$, followed by diabetes $(19 \%)$. Most patients $(77 \%)$ received IL platinum-based combination treatment (most commonly gemcitabine + cisplatin, $83 \%$ ). Of those treated with $2 \mathrm{~L}$ treatment, $66 \%$ received a single agent (most commonly vinflunine, $71 \%$ ). Median OS $(95 \% \mathrm{Cl})$ with $1 \mathrm{~L}$ treatment was 16.1 months (13.7-19.2) overall and 17.7 months (14.4-24.2) with $1 \mathrm{~L}$ cisplatin + gemcitabine. In the $1 \mathrm{~L}$ setting, 12 -month OS was $61 \%, 24-$ month OS was $39 \%$ and
\end{abstract}


36-month OS was $26 \%$. Median $(95 \% \mathrm{Cl})$ OS with $2 \mathrm{~L}$ treatment was 9.2 months $(5.5-11.6)$ overall and 5.9 months $(4.1-12.6)$ with $2 \mathrm{~L}$ vinflunine. In the $2 \mathrm{~L}$ setting, $O S$ rates for the same time periods were $40 \%, 22 \%$ and $8 \%$, respectively. Median $(95 \% \mathrm{Cl})$ progression-free survival was 7 months (6.4-8.1) and 4 months (3.0-4.8), respectively, in the $1 \mathrm{~L}$ and $2 \mathrm{~L}$ settings. Objective response rates were $34 \%$ in the $1 \mathrm{~L}$ setting and $14 \%$ in the $2 \mathrm{~L}$ setting. No difference in OS by sex or smoking status was noted. Patients with or without renal impairment had a 12 -month OS of $54 \%$ or $69 \%$, respectively. OS at 12 months was $63 \%$ among patients with an Eastern Cooperative Oncology Group performance status (ECOG PS) of 0 to 1 vs $53 \%$ among patients with an ECOG PS of $\geq 2$. Cox regression analysis found no difference in OS between vinflunine and other $2 L$ treatments $(P=$ 0.69).

Conclusions: This study provides a contemporary multicenter assessment of real-world treatment patterns and outcomes among palliatively treated patients with UC in Germany. The findings were generally consistent with the poor treatment outcomes observed globally, underscoring the need for effective $1 \mathrm{~L}$ and $2 \mathrm{~L}$ treatment for advanced $U C$ or $m U C$.

Key words: first-line treatment, German clinical practice, metastatic urothelial carcinoma, second-line treatment, treatment patterns

\section{Introduction}

Globally, there were approximately 430,000 new cases of and 165,000 deaths due to bladder cancer in 2012 [1]; it was the ninth most common cancer among both sexes and was the thirteenth most common cause of death due to cancer [1]. The incidence and prevalence of bladder cancer varies widely across European countries [1, 2]. In Germany, urothelial carcinoma (UC) constitutes one of the most common cancers [3]. Based on 2012 data, Germany had the ninth highest international age-standardized incidence of bladder cancer in men and women [4]. For bladder cancer, of which UC accounts for $>90 \%$ of cases, an incidence of 28,910 newly diagnosed cases per year was reported in Germany, of which 15,400 were invasive [1, 4]. In Germany, non-UCs of the urinary bladder are infrequent $(<10 \%)[5,6]$. Similarly, $\mathrm{UC}$ of the upper urinary tract, ureters and renal pelvis accounts for $<10 \%$ of urothelial bladder cancers [7-9], with 2770 incident cases per year in Germany, in both sexes [10].

The clinical course of patients with UC varies widely, with approximately two-thirds of patients experiencing an uncomplicated clinical course due to a relatively low risk of invasion and metastasis. However, the remaining patients face an aggressive disease with often rapid local and systemic progression [1, 11]. As many as $50 \%$ to $70 \%$ of non-muscle-invasive bladder cancers recur, and approximately $10 \%$ to $20 \%$ progress to muscle-invasive disease $[1,12]$ that may portend a worse prognosis. For instance, according to the large US-based Surveillance, Epidemiology, and End Results Program of the National Cancer Institute, approximately $34 \%$ of bladder cancers are localized and associated with a 5-year survival of approximately $70 \%$. Comparatively, patients with regional $(7 \%$ of diagnoses) or distant $(4 \%$ of diagnoses) spread have 5-year survival rates of $35 \%$ and $5 \%$, respectively [13].

In the palliative setting, cisplatin-based combination chemotherapy is the standard first-line (1L) treatment [11], and median overall survival (mOS) with such regimens is 13 to 16 months [11, 14-16]. However, cisplatin eligibility remains a limiting factor in elderly patients because renal dysfunction (creatinine clearance [CrCL] $<60$ $\mathrm{mL} / \mathrm{min}$ ), poor performance status (Eastern Cooperative Oncology Group performance status [ECOG PS] of $\geq 2$ ) and comorbidities (eg, New York Heart Association Class III heart failure, grade $\geq 2$ hearing loss, grade $\geq 2$ neuropathy) exclude many patients $(\approx 50 \%)$ from recommended $1 \mathrm{~L}$ treatment [17-20]. Treatment of patients who progress after $1 \mathrm{~L}$ treatment remains a challenge, because second-line (2L) treatment options are limited. Current practice guidelines in Europe recommend vinflunine as $2 \mathrm{~L}$ treatment $[11,17]$; however, $2 \mathrm{~L}$ treatment of mUC varies geographically because there is no global standard of care for 2L treatment. Vinflunine was approved by the European Medicines Agency in 2009 but is not used throughout all of Europe [21]. Support for vinflunine in the $2 \mathrm{~L}$ setting was based on the results from a phase 3 study showing that vinflunine + best supportive treatment resulted in an overall response rate of $8.6 \%$ compared with $0 \%$ with best supportive treatment alone [22]. Although no survival advantage was found in the intent-to-treat population $(\mathrm{n}=370)$, improvement in mOS favored vinflunine $(4$ vs 7 months) in the eligible population ( $\mathrm{n}=357$, which excluded 13 intent-to-treat patients who had $\geq 1$ major protocol violation at baseline; $P=0.036$ ) [22]. In countries where vinflunine is not approved, including 
the United States, taxanes or taxane-based combinations are considered an appropriate alternative [11, 23, 24].

Data are limited on treatment patterns and outcomes in patients with advanced UC or metastatic UC (mUC) in the routine clinical setting in Germany. The primary objective of this retrospective, observational cohort analysis was to describe treatment patterns and survival outcomes among patients with a diagnosis of incurable locally advanced UC or mUC treated with $1 \mathrm{~L}$ and $2 \mathrm{~L}$ systemic chemotherapy in the palliative setting in Germany.

\section{Materials and Methods}

\section{Study design}

This noninterventional, retrospective analysis evaluated the $1 \mathrm{~L}$ and $2 \mathrm{~L}$ treatments and survival outcomes of patients with locally advanced UC or mUC in the real-world clinical practice setting in Germany. The study protocol (MO39086) was approved by the ethics committee at the Medical Faculty of the Heinrich-Heine-University Düsseldorf (study number 5566). The protocol was conducted in accordance with the Declaration of Helsinki and Good Clinical Practice Guidelines.

\section{Contributing databases}

Data for this study were obtained through 2 sources, and the overall study and observation periods are outlined in Figure S1. The GermanOncology (GO) network contributed data from office-based urology clinics, distributed across Germany, which collect patient characteristics, treatment data and outcome data using a standardized electronic case report form (eCRF). The GO database began in January 2012 and currently includes patient clinical characteristics, chemotherapy and radiotherapy treatment regimens, comorbid conditions and supportive therapy use from $>12,500$ patients being treated for cancer. To reach the appropriate sample size of patients with advanced or mUC, 25 additional treatment centers were recruited to contribute patient data by means of a modified eCRF. This modified eCRF extended the GO eCRF to enable more tailored and detailed data collection by including prognostic variables (eg, PS, hemoglobin, $\mathrm{CrCl}$ and site of metastases). For the newly accrued patients from these additional data sources, only data from up to June 2, 2016 (submission of protocol to institutional review boards) were considered in accordance with the requirements of the ethical permission obtained for the study.

\section{Patient population and definitions}

Eligible patients included adults aged $\geq 18$ years with a diagnosis of locally advanced (transitional cell) UC of the upper and lower urinary tracts, defined as $\mathrm{T} 4 \mathrm{~b}, \mathrm{~N}($ any), M0, T(any), N2-3, M0 or metastatic cancer defined as $\mathrm{T}$ (any), N(any), M1 (with clinical, radiological or pathological confirmation of metastasis) who received palliative $1 \mathrm{~L}$ or $2 \mathrm{~L}$ treatment starting on or after November 1, 2009 (Figure S1). Patients were excluded if their medical records were missing data on critical variables (Figure 1). Critical variables included age, sex, stage at study entry, line of therapy, start date of first or second line of therapy, end date of $1 \mathrm{~L}$ or $2 \mathrm{~L}$ treatment and therapeutic agents. Patients included in this registry were eligible for $1 \mathrm{~L}$, 2L or both cohorts depending on the treatments (lines of therapy) received. Patients in the $2 \mathrm{~L}$ cohort, if data were complete for their $1 \mathrm{~L}$ treatment, were also included in the $1 \mathrm{~L}$ analysis if otherwise eligible for that analysis. Patients with nonmuscle invasive bladder cancer were not included.

\section{Treatment and outcome definitions}

For $1 \mathrm{~L}$ treatment, the index date for study participants was the start date of the 1L systemic treatment. For 2L treatment, the index date was the date when the $2 \mathrm{~L}$ chemotherapeutic treatment for recurrence after previous treatments/treatment failure of 1L treatment was initiated (Figure S1). Treatment response was assessed by the treating physician. The objective response rate was defined as the number of patients with a complete or partial response divided by the total number of patients.

\section{Statistical analysis}

Results for treatment patterns and clinical characteristics were reported as the numbers and percentages of patients, and descriptive analyses including means and SDs or $95 \%$ CIs and/or medians and interquartile ranges (Q1-Q3) were used for continuous variables. The numbers and percentages of patients were used for categorical variables. All statistical analyses were conducted using SAS 9.4.

\section{Survival analyses}

OS was defined as the interval between the index date of $1 \mathrm{~L}$ treatment or $2 \mathrm{~L}$ treatment and the date of death; patients lost to follow-up or alive at the end of the study period were censored at the last available date known to be alive. The mOS was estimated in months using the Kaplan-Meier method with 95\% CIs. Milestone survival rates at 6, 12, 24 and 36 months were calculated with $95 \%$ CIs around the estimates using the Life Table (actuarial) method. 
Cox regression analysis was used to compare outcomes in patients receiving vinflunine with other $2 \mathrm{~L}$ treatments, adjusted for hypothesized prognostic factors based on the vinflunine phase 3 study (ECOG PS [ $>0$ vs 0 ], liver metastases [yes vs no], hemoglobin level $[<10$ vs $\geq 10 \mathrm{~g} / \mathrm{dL}$ ), age at index ( $\geq 68$ vs $<68$ years) and sex [25]. Patients with missing covariates in the Cox regression were excluded from the regression analysis. All prognostic factors were included in the model at the same time. However, because information on hemoglobin level was not available for patients from the GO database, survival differences between vinflunine vs any other non-vinfluninecontaining therapy using the Bellmunt model could only be assessed in a subset of the total 2L-treated patient population.

Progression-free survival (PFS) was measured from the index date to the date of progression or death due to any cause or initiation of new regimen, censoring patients who were still alive and did not progress at the last visit date. Median PFS (mPFS) was estimated, with 95\% CIs, in months using the Kaplan-Meier method.

\section{Results}

\section{Sites and geographic representation}

Care settings included office-based sites (1L: 229 patients; 2L: 61 patients), nonacademic clinics (1L: 70 patients; 2L: 8 patients) and academic clinics (1L: 136 patients; 2L: 56 patients). Contributing centers covered most of Germany in a manner reflecting the distribution of the population. As such, most patients came from North Rhine-Westphalia ( $\mathrm{n}=183,42 \%)$, followed by Bavaria $(n=42,10 \%)$ and Berlin $(n=63$, $15 \%)$, which are all densely populated federal states. A large hospital in Berlin provided coverage to patients in nearby Mecklenburg-Vorpommern and Brandenburg. Less densely populated states such as Saxony-Anhalt $(n=19,4 \%)$ or Saxony $(n=5,1 \%)$ had a lower contribution of patients, and federal states that were not covered mainly reflect low-populated states such as Saarland or Thuringia.

\section{Patient population and baseline characteristics}

Of the 444 eligible patients, 9 were excluded for missing data on critical variables during $1 \mathrm{~L}$ treatment. Overall, 435 patients were included in the $1 \mathrm{~L}$ analysis, of which 125 were also included in the analysis of $2 \mathrm{~L}$ treatment. Details of patient attrition by data source are shown in Figure 1. In general, of the 184 patients with UC extracted from the GO database, 118 met the inclusion criteria-112 of whom received $1 \mathrm{~L}$ chemotherapy and 30 of whom received $2 \mathrm{~L}$ chemotherapy. Of the 326 patients obtained from the other contributing centers, all met the inclusion criteria - of whom 323 received 1L chemotherapy and 95 received 2L chemotherapy (Figure 1).

In patients treated with $1 \mathrm{~L}$ treatment, the mean age was 66 years at the time of primary diagnosis and 67.4 years at the time of $1 \mathrm{~L}$ treatment (Table 1 ). Patients treated with 2L chemotherapy had a mean age of 64.3 years at the time of initial diagnosis and of 66.6 years at the time of $2 \mathrm{~L}$ index date. The majority of $1 \mathrm{~L}$ - and 2L-treated patients were male, were current or former smokers and had metastatic (M1) disease (Table 1). A large number of patients had missing baseline smoking status ( $\mathrm{n}=225,52 \%), \mathrm{CrCl}$ levels ( $\mathrm{n}$ $=183,42 \%)$ and hemoglobin levels $(n=182,42 \%)$. The most common distant metastatic sites in 1L-treated patients were the liver $(42 \%)$ and other visceral organs $(38 \%)$. In those who received $2 \mathrm{~L}$ treatment, the most common metastatic sites also included the liver (32\%), other visceral organs (30\%) and bone (30\%). A higher percentage of 2L-treated than 1L-treated patients had an ECOG PS of $\geq 2, \mathrm{CrCl}<60 \mathrm{~mL} / \mathrm{min}$ and hemoglobin $<10 \mathrm{mg} / \mathrm{dL}$ (Figure 2A). The most common comorbidities were cardiovascular disease, diabetes and renal insufficiency, which were similar in frequency between the $1 \mathrm{~L}$ and $2 \mathrm{~L}$ treatment groups (Figure 2B, Table 1).

\section{Treatment patterns}

The median time from primary diagnosis to any $1 \mathrm{~L}$ palliative treatment was 4.9 months, and the median time from diagnosis to any $2 \mathrm{~L}$ palliative treatment was 7.5 months. A graphic illustration of treatment flow across $1 \mathrm{~L}, 2 \mathrm{~L}$ and $3 \mathrm{~L}$ treatments is provided in Figure 3. Approximately $77 \%(n=334)$ of 1L-treated patients received platinum-based combination treatment. The most common $1 \mathrm{~L}$ combination treatment was gemcitabine + cisplatin (n $=276,83 \%)$, followed by gemcitabine + carboplatin $(\mathrm{n}$ $=47,14 \%)$. A minority of patients $(\mathrm{n}=75,17.2 \%)$ were treated with $1 \mathrm{~L}$ single-agent treatment. Gemcitabine $(\mathrm{n}=38,51 \%)$ was the most common $1 \mathrm{~L}$ single agent, followed by vinflunine $(\mathrm{n}=12,16 \%)$ and cisplatin $(\mathrm{n}=$ $11,15 \%)$. In this analysis, approximately $29 \%(n=125)$ of 1L-treated patients received 2L treatment, and 9\% $(n=37)$ received $3 \mathrm{~L}$ treatment (Figure 3$)$. However, subsequent treatment data may not be fully captured due to ongoing treatment, progression or death, as discussed below. Of the 2L-treated patients, $66 \%(n=$ 83) received single-agent treatment. The most common was vinflunine $(\mathrm{n}=59,71 \%)$, followed by gemcitabine $(n=7,8 \%)$ and paclitaxel $(n=5,6 \%)$. Approximately one-third ( $\mathrm{n}=40,32 \%)$ of 2L-treated patients received combination treatment, and the most common combinations were gemcitabine + cisplatin $(n=15,37 \%)$, gemcitabine + paclitaxel $(n=$ $15,37 \%)$ and gemcitabine + carboplatin $(n=8,20 \%)$. 


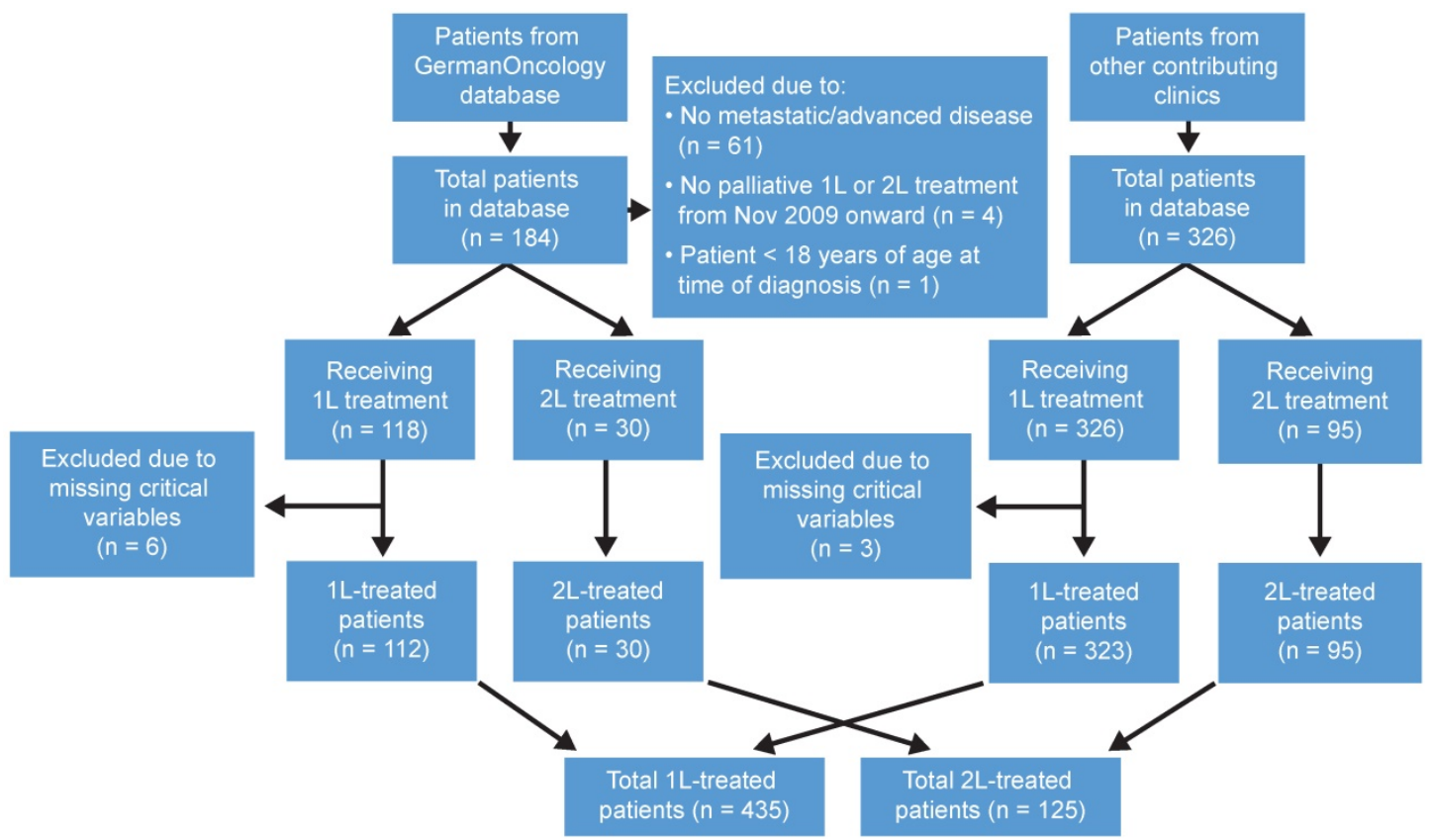

Figure 1. Patient attrition. Schematic flow diagram indicating study databases, reasons for exclusion and analysis populations. IL: first line; 2L: second line.

A
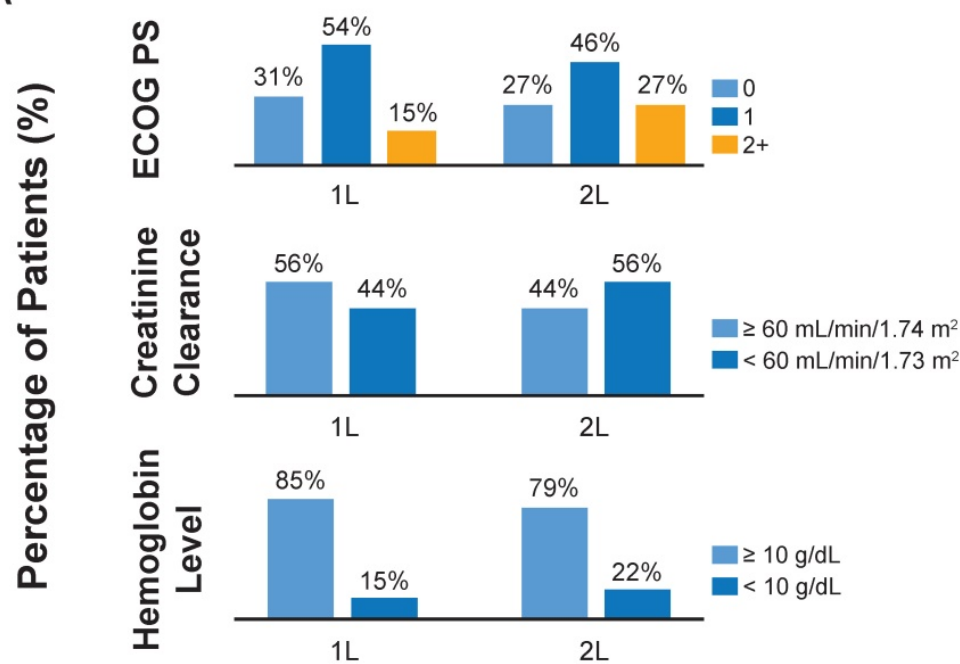

B
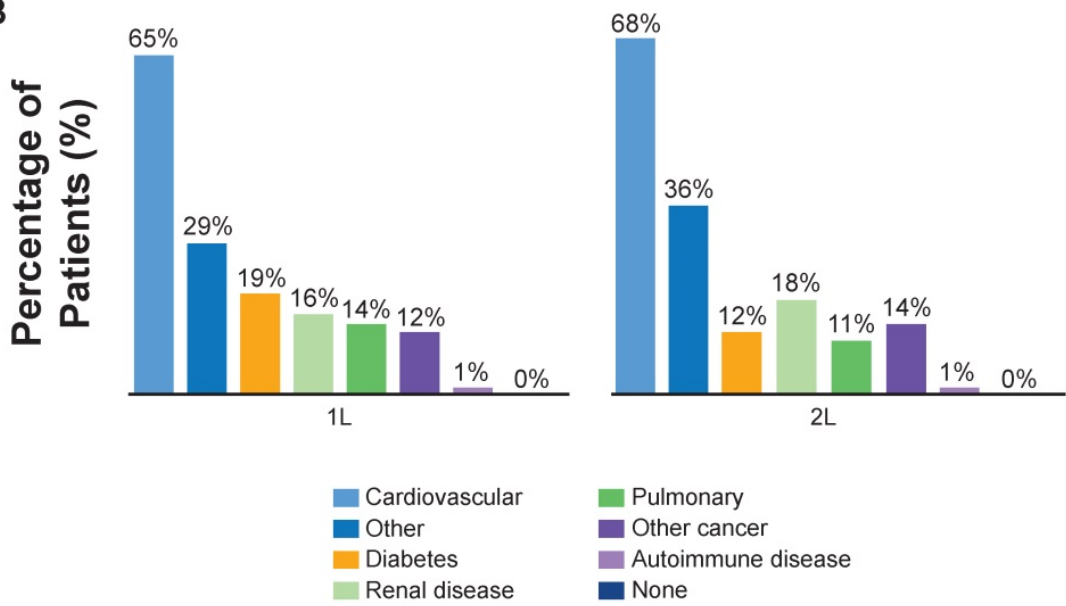

Pulmonary

Other cancer

Autoimmune disease

None

Figure 2. Baseline characteristics and comorbidities by line of therapy. (A) Eastern Cooperative Oncology Group performance status (ECOG PS), creatinine clearance and hemoglobin levels by line of therapy. Percentages of patients with missing baseline ECOG PS, creatinine clearance and hemoglobin were $7 \%, 42 \%$ and $42 \%$, respectively. (B) Common comorbidities by line of therapy. 
Table 1. Baseline characteristics by line of therapy and most common $1 \mathrm{~L}$ and $2 \mathrm{~L}$ treatments

\begin{tabular}{|c|c|c|c|c|}
\hline Characteristic & $\begin{array}{l}\text { Patients With } \\
\text { 1L Treatment }\end{array}$ & $\begin{array}{l}\text { 1L Cisplatin } \\
+ \text { Gemcitabine }^{\mathrm{a}}\end{array}$ & Patients With 2L Treatment & 2L Vinflunine ${ }^{b}$ \\
\hline Patient count at start, $\mathrm{n}$ & 435 & 276 & 125 & 59 \\
\hline \multicolumn{5}{|l|}{ Age at primary diagnosis, yearsc } \\
\hline Mean (SD) & $66.0(10)$ & $64.9(9)$ & $64.3(10)$ & $65.1(10)$ \\
\hline Median & 67 & 66 & 65 & 67 \\
\hline \multicolumn{5}{|l|}{ Age at index date, years ${ }^{d}$} \\
\hline Mean (SD) & $67.4(10)$ & $66.2(9)$ & $66.6(10)$ & $66.6(10)$ \\
\hline Median & 69 & 67 & 69 & 69 \\
\hline \multicolumn{5}{|l|}{ Baseline characteristic, n (\%) } \\
\hline \multicolumn{5}{|l|}{ Sex } \\
\hline Male & $326(75)$ & $204(74)$ & $87(70)$ & $40(68)$ \\
\hline Female & $109(25)$ & $72(26)$ & $38(30)$ & $19(32)$ \\
\hline \multicolumn{5}{|l|}{ Smoking status } \\
\hline Never & $53(25)$ & $27(18)$ & $18(32)$ & $9(35)$ \\
\hline Current/former & $157(75)$ & $122(82)$ & $39(68)$ & $17(65)$ \\
\hline Missing & $225(52)$ & $127(46)$ & $68(54)$ & $33(56)$ \\
\hline \multicolumn{5}{|l|}{ Tumor stage at study entry } \\
\hline $\begin{array}{l}\text { IV (only IV is permitted, } \\
\text { if available) }\end{array}$ & $363(100)$ & $260(100)$ & $103(100)$ & $46(100)$ \\
\hline Missing & $72(17)$ & $16(6)$ & $22(18)$ & $13(22)$ \\
\hline \multicolumn{5}{|l|}{ Primary tumor grade } \\
\hline Low grade & $299(931)$ & $235(96)$ & $889(94)$ & $40(98)$ \\
\hline High grade & $22(7)$ & $9(4)$ & $6(6)$ & $1(2)$ \\
\hline Missing & $114(26)$ & $32(12)$ & $31(25)$ & $18(31)$ \\
\hline \multicolumn{5}{|l|}{ Metastatic status at study entrye } \\
\hline M0 & $142(39)$ & $106(41)$ & $32(31)$ & $16(35)$ \\
\hline M1 primary & $136(37)$ & $97(37)$ & $33(32)$ & $16(35)$ \\
\hline M1 recurrent & $89(24)$ & $58(22)$ & $39(38)$ & $14(30)$ \\
\hline Missing & $68(16)$ & $15(5)$ & $21(17)$ & $13(22)$ \\
\hline \multicolumn{5}{|l|}{ Extent of disease at study entryf } \\
\hline $\begin{array}{l}\text { Locally advanced, moderate } \\
\text { lymph node involvement }{ }^{f}\end{array}$ & $9(2)$ & $8(3)$ & $4(3)$ & $2(3)$ \\
\hline $\begin{array}{l}\text { Bladder confined, extensive } \\
\text { lymph node involvement }{ }^{f}\end{array}$ & $133(31)$ & $98(36)$ & $28(22)$ & $14(24)$ \\
\hline \multicolumn{5}{|c|}{ Location of distant metastasis (if M1) } \\
\hline Liver & $56(42)$ & $44(48)$ & $17(34)$ & $8(38)$ \\
\hline Other visceralg & $50(38)$ & $31(34)$ & $15(30)$ & $7(33)$ \\
\hline Bone & $41(31)$ & $30(33)$ & $15(30)$ & $5(24)$ \\
\hline Other nonvisceralg & $33(25)$ & $20(22)$ & $14(28)$ & $5(24)$ \\
\hline Missing & $93(41)$ & $63(41)$ & $22(31)$ & $9(30)$ \\
\hline \multicolumn{5}{|l|}{ ECOG PS } \\
\hline 0 & $125(31)$ & $96(36)$ & $31(27)$ & $18(33)$ \\
\hline 1 & $218(54)$ & $141(52)$ & $54(46)$ & $18(33)$ \\
\hline $2+$ & $62(15)$ & $32(12)$ & $32(27)$ & $18(33)$ \\
\hline Missing & $30(7)$ & $7(3)$ & $8(6)$ & $5(8)$ \\
\hline \multicolumn{5}{|l|}{ Hemoglobin level } \\
\hline$<10 \mathrm{~g} / \mathrm{dL}$ & $39(15)$ & $29(15)$ & $17(22)$ & $6(17)$ \\
\hline$\geq 10 \mathrm{~g} / \mathrm{dL}$ & $214(85)$ & $161(85)$ & $62(78)$ & $29(83)$ \\
\hline Missing & $182(42)$ & $86(31)$ & $46(37)$ & $24(41)$ \\
\hline \multicolumn{5}{|l|}{$\mathrm{CrCl}$} \\
\hline$<60 \mathrm{~mL} / \mathrm{min} / 1.73 \mathrm{~m}^{2}$ & $110(44)$ & $71(38)$ & $45(56)$ & $22(61)$ \\
\hline$\geq 60 \mathrm{~mL} / \mathrm{min} / 1.73 \mathrm{~m}^{2}$ & $142(56)$ & $118(62)$ & $35(44)$ & $14(39)$ \\
\hline Missing & $183(42)$ & $87(32)$ & $45(36)$ & $2(39)$ \\
\hline \multicolumn{5}{|l|}{ Comorbiditiese,h } \\
\hline Pulmonary & $46(14)$ & $26(12)$ & $10(11)$ & $5(11)$ \\
\hline Cardiovascular & $222(65)$ & $128(60)$ & $64(68)$ & $32(70)$ \\
\hline Diabetes & $66(19)$ & $49(23)$ & $11(12)$ & $6(13)$ \\
\hline Renal disease & $53(16)$ & $23(11)$ & $17(18)$ & $8(17)$ \\
\hline Autoimmune disease ${ }^{i}$ & $4(1)$ & $4(2)$ & $1(1)$ & $0(0.0)$ \\
\hline Other & $100(29)$ & $59(27)$ & $34(36)$ & $16(35)$ \\
\hline Other cancer & $41(12)$ & $21(10)$ & $13(14)$ & $8(17)$ \\
\hline Missing & $93(21)$ & $61(22)$ & $31(25)$ & $13(22)$ \\
\hline \multicolumn{5}{|l|}{ Insurance type } \\
\hline Private & $48(11)$ & $29(11)$ & $20(16)$ & $7(12)$ \\
\hline Public & $387(89)$ & $247(90)$ & $105(84)$ & $52(88)$ \\
\hline
\end{tabular}


c Primary diagnosis was the initial diagnosis of urothelial carcinoma, independent of stage.

d For $1 \mathrm{~L}$ treatment, the index date was the start date of the $1 \mathrm{~L}$ systemic treatment. For $2 \mathrm{~L}$ treatment, the index date was the date when the $2 \mathrm{~L}$ chemotherapeutic treatment for recurrence after previous treatments/treatment failure of $1 \mathrm{~L}$ treatment was initiated.

e Values within categories do not necessarily add up to $100 \%$ due to non-mutually exclusive groups and/or missing values, which do not contribute to the denominators used for percentages.

${ }^{\mathrm{f}}$ For patients with non-M1 or non-missing status. Locally advanced disease with moderate lymph node involvement refers to $\mathrm{Tb}, \mathrm{N} \leq 1, \mathrm{M} 0$ (incudes $\mathrm{Nx}$ or $\mathrm{Mx}$, if $\mathrm{T} 4 \mathrm{~b}$ confirmed). Bladder-confined disease with extensive lymph node involvement refers to T4b, N2-3 M0 (includes Tx or Mx if N2-3 confirmed)

$\mathrm{g}$ Other metastatic sites, including the lung, peritoneum, non-visceral: brain, skin and otdher sites.

$\mathrm{h}$ Variable not collected by GermanOncology; total $\mathrm{N}=112$ for $1 \mathrm{~L}$ and 30 for $2 \mathrm{~L}$.

i Including $\geq 1$ of the following diseases: myasthenia gravis, myositis, autoimmune hepatitis, systemic lupus erythematosus, rheumatoid arthritis, inflammatory bowel disease, vascular thrombosis associated with anti-phospholipid syndrome, Wegener granulomatosis, Sjögren syndrome, Guillain-Barré syndrome, multiple sclerosis, vasculitis or glomerulonephritis.

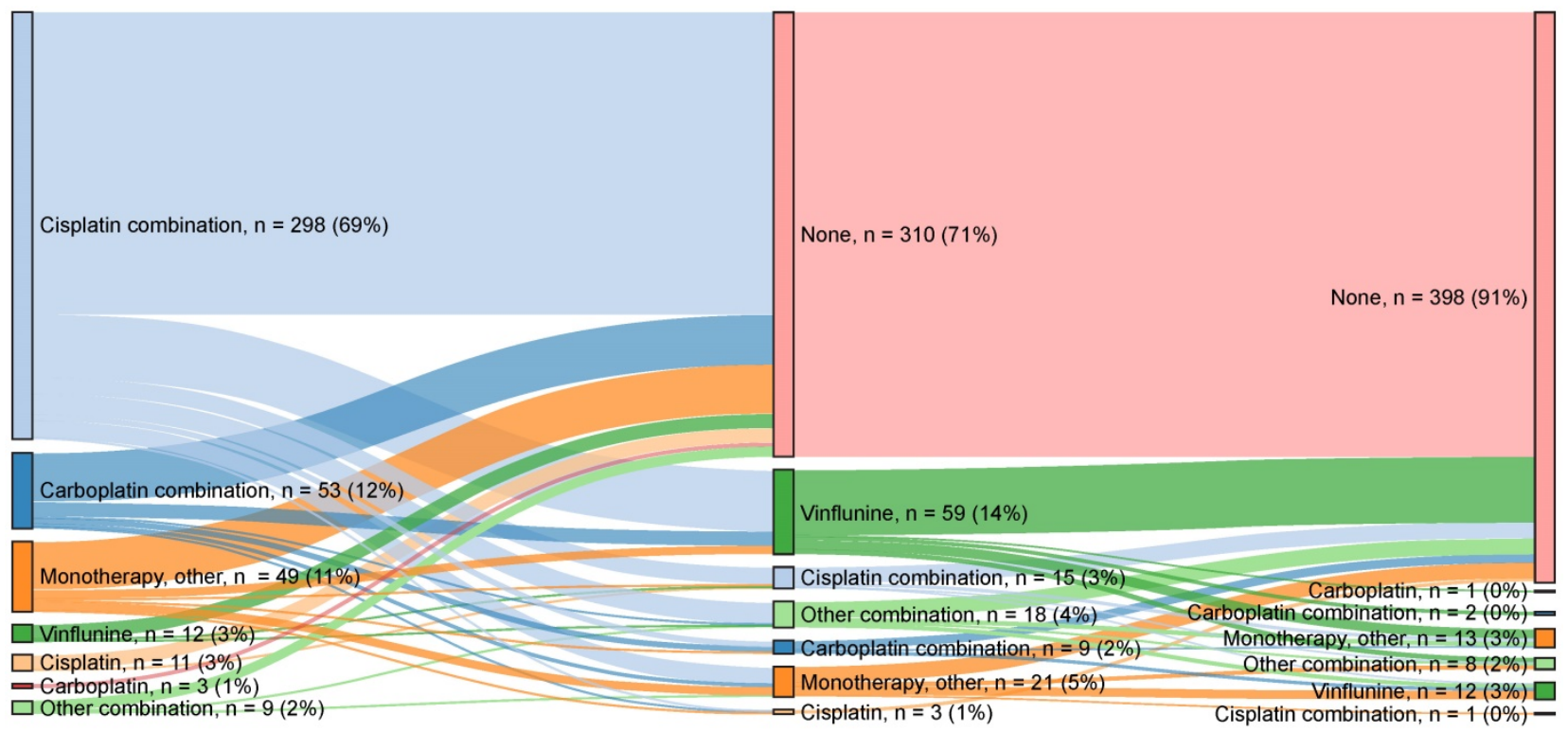

Figure 3. Treatment patterns across lines of therapy. Sankey diagram of treatments received. Possible reasons for not receiving second-line treatment include death, still receiving first-line treatment, clinical factors and patient preference.

\section{Treatment outcomes}

\section{OS by treatment type}

OS by line of treatment and most common vs other treatments is shown in Figure 4A. Of the patients who received $1 \mathrm{~L}$ treatment, a total of 206 (47\%) deaths occurred, and a total of $229(53 \%)$ were censored. Of the patients who received $2 \mathrm{~L}$ treatment, a total of $79(63 \%)$ deaths occurred and $46(37 \%)$ were censored. The mOS $(95 \% \mathrm{CI})$ with $1 \mathrm{~L}$ treatment overall was 16.1 months (13.7-19.2) and with cisplatin + gemcitabine was 17.7 months (14.4-24.2) (Table 2). In the $1 \mathrm{~L}$ setting, OS rates at 6, 12, 24 and 36 months were $80 \%, 61 \%, 39 \%$ and $26 \%$, respectively (Figure $4 \mathrm{~A})$. The mOS (95\% CI) with $2 \mathrm{~L}$ treatment overall was 9.2 months (5.5-11.6) and 5.9 months (4.1-12.6) with 2L vinflunine (Table 2). In the $2 \mathrm{~L}$ setting, OS rates at the same time periods were $57 \%, 40 \%, 22 \%$ and $8 \%$, respectively. Survival rates with the $1 \mathrm{~L}$ combination of gemcitabine + cisplatin at 6, 12, 24 and 36 months were $82 \%, 66 \%, 43 \%$ and $26 \%$, respectively. OS was numerically higher for the combination of gemcitabine + cisplatin at 6 and 12 months compared with other $1 \mathrm{~L}$ treatments. This difference became less apparent at 24 and 36 months. OS with 2L treatment with vinflunine was similar to that with other $2 \mathrm{~L}$ agents at all time points. OS rates with vinflunine at 6 , 12,24 and 36 months were $49 \%, 39 \%, 20 \%$ and $9 \%$, respectively, in the $2 \mathrm{~L}$ setting (Figure $4 \mathrm{~A}$ ). Cox multivariate regression analysis found no difference in survival between vinflunine and other $2 \mathrm{~L}$ treatments (adjusted $P$ value $=0.69)($ Figure 5A).

\section{OS by clinical characteristics}

OS in the $1 \mathrm{~L}$ setting was similar by age $(<65$ or $\geq 65$ years) at 6,12 and 24 months and was numerically higher at 36 months in favor of patients aged $<65$ years (Figure 4B). OS at 6, 12, 24 and 36 months was similar by sex and smoking status (Figure 4B). In 1L-treated patients, those without renal insufficiency had numerically higher OS at 6 and 12 months but not thereafter. In 1L-treated patients, survival appeared higher in patients with an ECOG PS of 0 to 1 compared with an ECOG PS of $\geq 2$ (Figure 4C). No difference in survival in the $2 \mathrm{~L}$ setting was found based on Bellmunt risk factors [25] (Figure 5B).

\section{Treatment response and progression by line of therapy}

Key measures of response and progression by line of therapy are shown in Table 2. Objective 
responses occurred in $34 \%$ of patients treated with any $1 \mathrm{~L}$ treatment, $35 \%$ of patients treated with $1 \mathrm{~L}$ cisplatin + gemcitabine, $13 \%$ of 2L-treated patients and $5 \%$ of patients treated with $2 \mathrm{~L}$ vinflunine (Table 2). The mPFS $(95 \% \mathrm{CI})$ values in patients treated with any $1 \mathrm{~L}$ treatment, $1 \mathrm{~L}$ cisplatin + gemcitabine, any $2 \mathrm{~L}$ treatment and 2L vinflunine were 7 months (6.4-8.1), 7 months (6.4-9.1), 4 months (3.0-4.8) and 3 months (2.5-4.2), respectively. Of the patients who received $1 \mathrm{~L}$ treatment, a total of 228 (66\%) PFS events (death or progression) occurred, and 147 (34\%) were censored. In the patients who received 2L treatment, a total of 99 $(79 \%)$ PFS events (death or progression) occurred -26 $(21 \%)$ of which were censored. Early disease progression within 6 and 12 months of start of treatment occurred in $26 \%(n=115)$ and $43 \%(n=186)$ of patients treated in the $1 \mathrm{~L}$ setting and in $43 \%(n=54)$ and $55 \%(\mathrm{n}=69)$ of patients treated with $2 \mathrm{~L}$ chemotherapy, respectively (Table 2).

A Line of therapy and most frequent treatment vs. other treatments

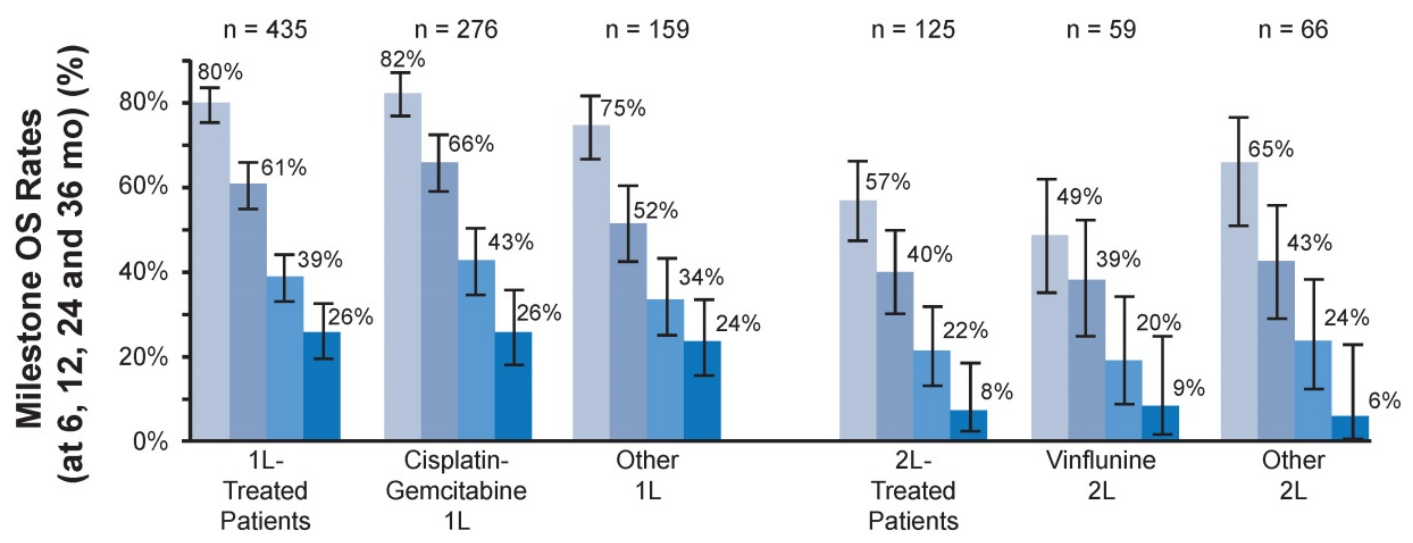

B 1 L therapy by age, sex and smoking status subgroup

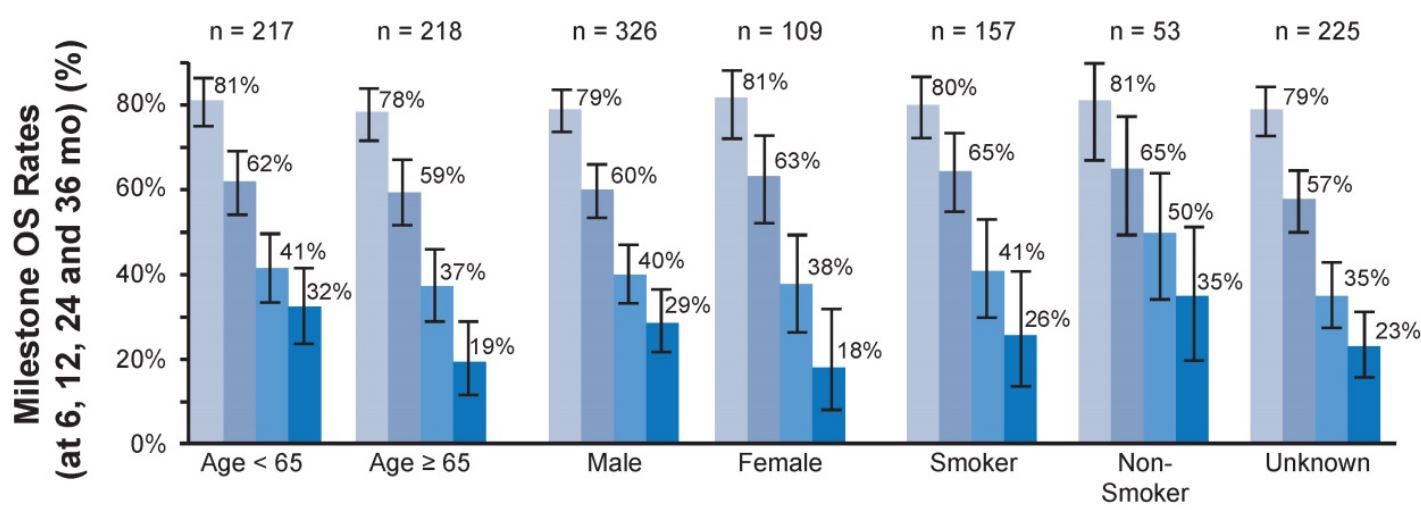

C $1 \mathrm{~L}$ therapy by renal function and ECOG PS

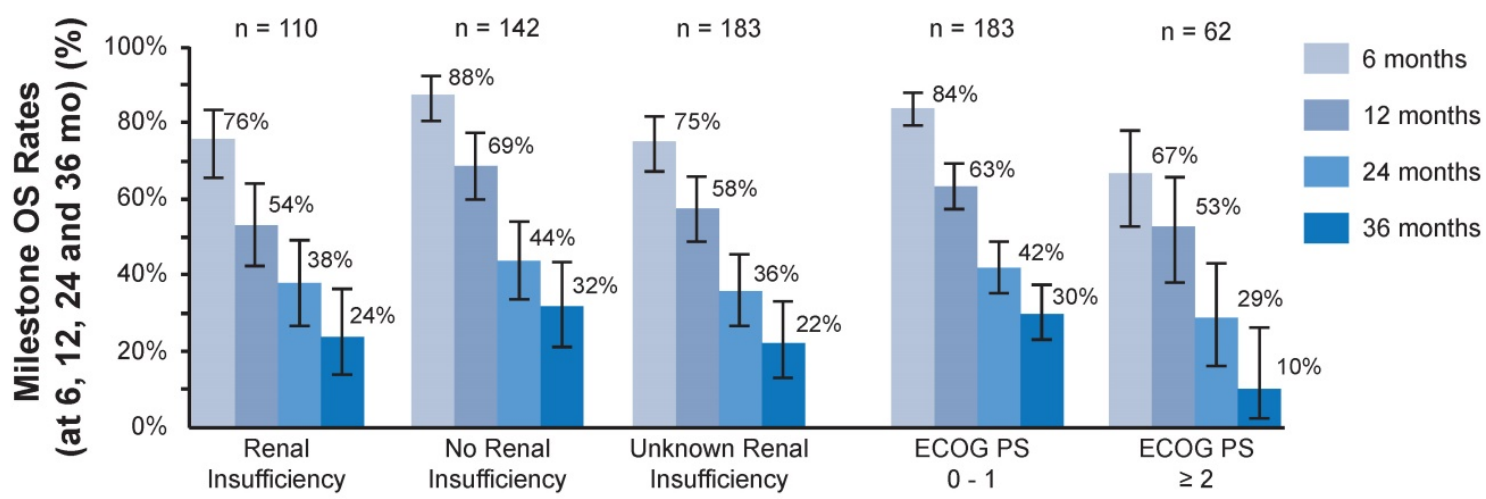

Figure 4. First-line (1L) treatment outcomes. (A) Milestone overall survival (OS) at 6, 12, 24 and 36 months by line of therapy and most frequent vs other treatments. (B) Milestone OS at 6, 12, 24 and 36 months for $1 \mathrm{~L}$ treatment by age, sex and subgroups of smoking status. (C) Milestone OS at $6,12,24$ and 36 months for $1 \mathrm{~L}$ treatment by renal function and Eastern Cooperative Oncology Group performance status (ECOG PS). Bars show $95 \%$ Cls. 
Table 2. Clinical outcomes by line of therapy

\begin{tabular}{|c|c|c|c|c|}
\hline & $\begin{array}{l}\text { 1L-Treated Patients } \\
(\mathrm{n}=435)\end{array}$ & $\begin{array}{l}\text { 1L Cisplatin } \\
\text { + Gemcitabine } \\
(\mathrm{n}=276)\end{array}$ & $\begin{array}{l}\text { 2L-Treated Patients } \\
(\mathrm{n}=125)\end{array}$ & $\begin{array}{l}\text { 2L Vinflunine } \\
(\mathrm{n}=59)\end{array}$ \\
\hline PFS, median (95\% CI), months & $7.2(6.4-8.1)$ & $7.6(6.4-9.1)$ & $4.0(3.0-4.8)$ & $3.1(2.5-4.2)$ \\
\hline OS, median (95\% CI), months & $16.1(13.7-19.2)$ & $17.7(14.4-24.2)$ & $9.2(5.5-11.6)$ & $5.9(4.1-12.6)$ \\
\hline Objective response, $\mathrm{n}(\%)^{\mathrm{c}}$ & $117(34)$ & $86(35)$ & $15(14 \%)$ & $3(6)$ \\
\hline \multicolumn{5}{|l|}{ Best overall response rate, $\mathrm{n}(\%)^{\mathrm{d}}$} \\
\hline Complete response & $38(11)$ & $29(12)$ & $2(2)$ & $0(0.0)$ \\
\hline Partial response & $79(22)$ & $57(23)$ & $13(12)$ & $3(6)$ \\
\hline Stable disease & $89(26)$ & $62(25)$ & $29(26)$ & $16(30)$ \\
\hline Progressive disease & $104(30)$ & $76(31)$ & $45(41)$ & $26(48)$ \\
\hline Not clearly definable & $38(11)$ & $21(9)$ & $22(20)$ & $9(17)$ \\
\hline Missing or unknown & $87(20)$ & $31(11)$ & $14(11)$ & $5(9)$ \\
\hline \multicolumn{5}{|l|}{ Early disease progression, $\mathrm{n}(\%)$} \\
\hline 6 months & $115(26)$ & $78(28)$ & $54(43)$ & $28(47)$ \\
\hline 12 months & $186(43)$ & $131(47)$ & 69 (55) & $34(58)$ \\
\hline
\end{tabular}

a Most common first-line treatment.

b Most common second-line treatment.

c Defined as the number of patients who achieved a complete or partial response (with percentages based on the total number of patients).

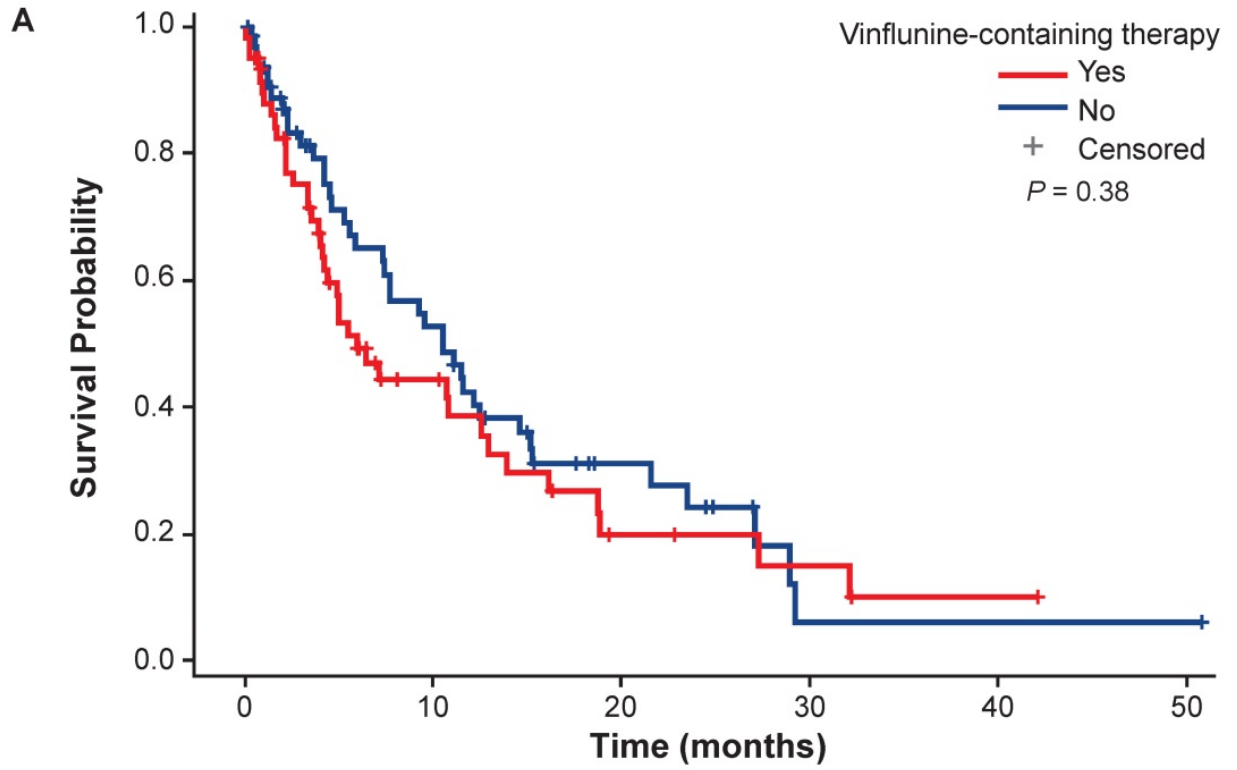

\begin{tabular}{|l|c|c|}
\hline B & \multicolumn{2}{|l|}{ Adjusted multivariate model including prognostic factors suggested by Bellmunt [25], $\mathrm{n}=\mathbf{7 0}^{\mathrm{a}}$} \\
\hline Prognostic Factors, & Hazard Ratio $(\mathbf{9 5 \%} \mathbf{C l})$ & $\mathbf{P}$ Value \\
\hline Vinflunine vs other therapy & $\mathbf{1 . 1 5}(\mathbf{0 . 5 8 - 2 . 2 5 )}$ & $\mathbf{0 . 6 9}$ \\
\hline Age at index $\geq$ vs $<68$ years & $0.45(0.23-0.88)$ & 0.02 \\
\hline Female vs male & $1.90(0.92-3.86)$ & 0.08 \\
\hline ECOG PS $>0$ vs 0 & $1.38(0.57-3.38)$ & 0.49 \\
\hline Liver metastasis yes vs no & $0.95(0.32-2.41)$ & 0.92 \\
\hline Hemoglobin $<10$ vs $\geq 10 \mathrm{~g} / \mathrm{dL}$ & $0.68(0.18-1.90)$ & 0.51 \\
\hline
\end{tabular}

Figure 5. Cox regression analysis comparing overall survival with second-line vinflunine vs other second-line treatments. (A) Overall survival analysis comparing second-line vinflunine-treated vs other treatments. (B) Cox regression analysis using the Bellmunt prognostic model for vinflunine vs other second-line treatments. a 70 patients remained after all patients with missing covariates were excluded. b The model was stratified by center type. $c$ The reference groups for each factor were as follows: other therapy, age $<68$ years, male sex, ECOG $=0$, no liver metastasis, hemoglobin $\geq 10$ g/dL. ECOG PS: Eastern Cooperative Oncology Group performance status.

\section{Discussion}

In this analysis, baseline characteristics and demographics of patients with advanced UC or mUC in Germany were consistent with expectations ( $>65$ years of age, mostly male and current or former smoker) $[11,13,17]$. The $1 \mathrm{~L}$ treatment regimens were also consistent with international guideline recommendations, as the majority of patients were treated with $1 \mathrm{~L}$ cisplatin-based combination treatment (71\%) $[11,17]$.

Furthermore, the remaining patients were preferably treated with carboplatin-based combinations, most commonly carboplatin + 
gemcitabine. Although high estimated rates of cisplatin ineligibility $(\approx 50 \%)$ have been reported [26], it is interesting to note that in our study the combination of gemcitabine + cisplatin was the most common 1L treatment among patients with an ECOG PS of $\geq 2$ and renal insufficiency (CrCL $<60 \mathrm{~mL} / \mathrm{min}$ ) (76\% and $79 \%$ ). Patients with these characteristics could be considered cisplatin ineligible [18-20] and could be excluded from randomized clinical trials, suggesting different treatment patterns between randomized clinical trials and those in the real-world practice setting. Furthermore, the mOS in patients in this subgroup was worse than that in their healthier counterparts, reflecting the great medical need for these underrepresented patients (ECOG PS of 0 to 1 and $\geq 2=17.8$ and 12.6 months, respectively; $\mathrm{CrCl} \geq$ and $<60 \mathrm{~mL} / \mathrm{min}: 19.2$ and 12.8 months respectively; and no liver metastases and liver metastases: 14.9 and 11.0 months, respectively). Indeed, the high percentage of cisplatin-treated patients may be due to the common practice of administering cisplatin-based treatment to those technically ineligible given the superiority of cisplatin-based combination therapy in this setting [27].

In our study, the mPFS and mOS in all patients who received 1L treatment were 7.2 and 16.1 months, respectively, which is comparable with data from randomized clinical trials among patients with locally advanced UC or mUC (eg, mPFS of 8 months and mOS of 13 of 16 months $[15,16]$. Less than one-third $(29 \%)$ of $1 \mathrm{~L}$-treated patients went on to receive $2 \mathrm{~L}$ treatment. The 1L-treated patients who did not receive $2 \mathrm{~L}$ chemotherapy $(71 \%)$ may have experienced stable disease that did not require additional lines of therapy, may have experienced progressive disease and refused treatment, may have died before $2 \mathrm{~L}$ chemotherapy or may have not received $2 \mathrm{~L}$ chemotherapy for unknown reasons. Patients in our study who received any $2 \mathrm{~L}$ treatment had an mPFS and mOS of 4 and 9 months, respectively-in line with previously reported randomized data with taxanes and vinflunine: mPFS of 2 to 3 months and mOS of 6 to 7 months [22, 28]. In addition, our real-world results from Germany show the overall $2 \mathrm{~L}$ mOS $(\approx 9 \mathrm{mo})$ is in line with the $\approx 8$-mo mOS demonstrated in a US population-based study previously reported [29].

The most common 2L treatment in our study was single-agent vinflunine (71\%). This finding is consistent with current European guideline recommendations to offer vinflunine to patients progressing after platinum-based combination chemotherapy for metastatic disease [11]. In our study, the mOS $(95 \% \mathrm{CI})$ among patients treated with $2 \mathrm{~L}$ vinflunine $(\mathrm{n}=59)$ was 5.9 months $(4.1-12.6)$, shorter than that in those treated with any $2 \mathrm{~L}$ agents (9.2 months; 5.5-11.6; $\mathrm{n}=125)$. The mPFS was similar between the 2 groups: 3.1 and 4.0 months, respectively. These findings are consistent with those of contemporary studies that showed that mOS ranged from 5 to 10 months and mPFS from 2 to 6 months in patients with advanced UC treated with vinflunine [22, 30-34]. However, multivariate Cox regression analysis found no significant difference in OS between vinflunine and other 2L treatment regimens. However, results should be interpreted with caution due to small sample sizes. This finding agrees with data from a recent phase 3 trial comparing the checkpoint inhibitor pembrolizumab with the standard 2L chemotherapies vinflunine, docetaxel or paclitaxel. In this trial, the efficacy of standard $2 \mathrm{~L}$ chemotherapeutic drugs was similar as well in 2L-treated patients [35]. However, results from a phase 3 trial comparing atezolizumab versus chemotherapy in patients with locally advanced or mUC who progressed after platinum-based chemotherapy found that survival with vinflunine was better than hypothesized compared with taxane-based treatment [36].

This study had several strengths and limitations. The results presented here are descriptive, and any comparisons of outcomes should be interpreted with caution because the patients were treated in routine clinical practice and not randomized to treatment arms; thus, unmeasured confounding variables may exist. The practice patterns described here may be applicable to Germany but not generalizable to practice patterns outside of Germany. Differences in treatment patterns may exist between office and academic care settings, but were not differentiable in this analysis. No detailed safety data was available as this study focused on treatment patterns and efficacy outcomes. The sample sizes of the subgroups were small, so limited statistical analyses were conducted. This study described several outcomes, including objective response rate, treatment response, PFS and OS, which is unusual for observational research studies. However, a large number of patients had missing baseline characteristics that may have affected outcome estimates (OS and PFS) within a specific subgroup as well as estimates of best overall response. Data collection relied on eCRF and responses of physicians and their staff, who transferred information from patient medical records; not only could there have been bias in the selection of patient records from which to transcribe the data, but there could have been errors introduced when the eCRFs were completed.

Overall, the results of this and previous studies of advanced UC and mUC show that outcomes are 
generally poor, because progression after $1 \mathrm{~L}$ failure is common and portends a worse prognosis. Effective treatment options in $1 \mathrm{~L}$ and $2 \mathrm{~L}$ settings are scarce, and many patients do not receive $2 \mathrm{~L}$ treatment. These results underscore the large unmet need for new therapeutic options for patients who progress after $1 \mathrm{~L}$ treatment. Therefore, a better understanding of the real-world patterns of chemotherapy use and its impact on survival is warranted due to the emergence of cancer immunotherapy in the $1 \mathrm{~L}$ and $2 \mathrm{~L}$ settings $[35,37-41]$.

\section{Supplementary Material}

Supplementary figure S1.

http://www.jcancer.org/v09p1337s1.pdf

\section{Acknowledgements}

We thank Ling-I Hsu and Irmarie Reyes-Rivera for their contributions to the study. We thank the recruiting physicians and their teams for their efforts with the data collection: Dr. Dimitri Barski, Urologische Klinik, Lukaskrankenhaus Neuss, Neuss; Dr. med. Katrin Bothe, Klinik für Urologie und Kinderurologie, Universitätsklinikum SchleswigHolstein, Campus Kiel, Kiel; PD Dr. med. Gunhild von Amsberg, Zentrum für Onkologie, Medizinische Klinik und Poliklinik, Universitätsklinikum Hamburg-Eppendorf, Hamburg; PD Dr. med. Jan Lehmann, Urologische Gemeinschaftspraxis Prüner Gang, Kiel; Prof. Dr. Stefan Hautmann, Klinik für Urologie, Klinikum Lüdenscheid, Lüdenscheid; Prof. Dr. Christian Schwentner, Klinik für Urologie, Diakonie-Klinikum Stuttgart, Stuttgart; Prof. Dr. med. Axel Merseburger, Klinik für Urologie, Universitätsklinikum Schleswig-Holstein, Campus Lübeck, Lübeck; Prof. Dr. med. Axel Hegele, Klinik für Urologie und Kinderurologie, PhilippsUniversität Marburg, Marburg; Dr. med. Armin Leitenberger, Klinik für Urologie, Klinikum Wolfsburg, Wolfsburg; Dr. med. Thomas Kretz, Überörtliche Urologische Gemeinschaftspraxis Heinsberg/Hückelhoven, Betriebsstätte Heinsberg, Heinsberg; Dr. med. Wolfgang Rulf, Urologie Neandertal, Ortsübergreifende Gemeinschaftspraxis für Urologie, Praxis Erkrath-Hochdahl, Erkrath; PD Dr. med. Henrik Suttmann, Urologikum Hamburg, Hamburg; Dr. med. Matthias Schulze, Praxis Markkleeberg, Markkleeberg; Dr. med. Thomas Pulte, Urologische Praxis am Wasserturm, Würselen; Dr. med. Jörg Klier, Urologische Partnerschaft Köln, Köln; Dr. med. Eva Hellmis, Urologicum Duisburg, Duisburg; Dr. med Hans-Jürgen Hurtz, Gemeinschaftspraxis und Tagesklinik, Hämatologie/ Onkologie/Gastroenterologie, Halle (Saale); Dr. Clemens Schulte, Gemeinschaftspraxis für
Hämatologie und Onkologie, Dortmund. This study was sponsored by F. Hoffmann-La Roche, Ltd. Medical writing assistance for this manuscript was provided by Eric Berlin, MD, of Health Interactions, Inc, and funded by F. Hoffmann-La Roche, Ltd.

\section{Competing Interests}

Güenter Niegisch has served in a consulting or advisory role with Roche Pharma AG, has received research funding from $4 \mathrm{SC}$ and has received travel and accommodations from Pfizer. Shih-Wen Lin and Julie Pavlova are employees of Genentech and Roche and have stock ownership.

\section{References}

1. [Internet] International Agency for Research on Cancer. World Cancer Report 2014. http://publications.iarc.fr/Non-Series-Publications/World-CancerReports/World-Cancer-Report-2014.

2. Burger M, Catto JW, Dalbagni G, et al. Epidemiology and risk factors of urothelial bladder cancer. Eur Urol. 2013; 63(2): 234-241.

3. [Internet] International Agency for Research on Cancer. Country factsheets: Germany. 2012. http://eco.iarc.fr/eucan/Country.aspx?ISOCountryCd=276.

4. [Internet] Cancer in Germany. Cancer in Germany 2011/2012. http://www.krebsdaten.de/Krebs/EN/Content/Publications/Cancer_in_G ermany/cancer in germany node.html.

5. Chalasani V, Chin JL, Izawa JI. Histologic variants of urothelial bladder cancer and nonurothelial histology in bladder cancer. Can Urol Assoc J. 2009; $3(6$ Suppl 4): S193-8.

6. Klaile Y, Schlack K, Boegemann M, Steinestel J, Schrader AJ, Krabbe LM. Variant histology in bladder cancer: how it should change the management in non-muscle invasive and muscle invasive disease? Transl Androl Urol. 2016; 5(5): 692-701.

7. [Internet] Rouprêt M, Babjuk M, Böhle A, Burger M, Compérat E. European Association of Urology Guidelines on Urothelial Carcinomas of the Upper Urinary Tract. 2015. http://uroweb.org/wp-content/uploads/06-UTUC _druk_LR.pdf.

8. Siegel RL, Miller KD, Jemal A. Cancer statistics, 2015. CA Cancer J Clin. 2015; 65(1): 5-29.

9. Munoz JJ, Ellison LM. Upper tract urothelial neoplasms: incidence and survival during the last 2 decades. J Urol. 2000; 164(5): 1523-1525.

10. [Internet] Cancer in Germany. Cancer in Germany. 2016. http://www.krebsdaten.de/Krebs/DE/Content/Publikationen/Krebsgesch ehen/Krebsgeschehen_download.pdf?_blob=publicationFile.

11. Witjes AJ, Lebret T, Comperat EM, et al. Updated 2016 EAU Guidelines on Muscle-invasive and Metastatic Bladder Cancer. Eur Urol. 2017; 71(3): 462-475.

12. Isharwal S, Konety B. Non-muscle invasive bladder cancer risk stratification. Indian J Urol. 2015; 31(4): 289-296

13. [Internet] National Cancer Institute. SEER Cancer Stat Fact Sheets: bladder cancer. 2017. https://seer.cancer.gov/statfacts/html/urinb.html.

14. Loehrer P.J.Sr., Einhorn LH, Elson PJ, et al. A randomized comparison of cisplatin alone or in combination with methotrexate, vinblastine, and doxorubicin in patients with metastatic urothelial carcinoma: a cooperative group study. J Clin Oncol. 1992; 10(7): 1066-1073.

15. von der Maase H, Sengelov L, Roberts JT, et al. Long-term survival results of a randomized trial comparing gemcitabine plus cisplatin, with methotrexate, vinblastine, doxorubicin, plus cisplatin in patients with bladder cancer. J Clin Oncol. 2005; 23(21): 4602-4608.

16. Bellmunt J, von der Maase H, Mead GM, et al. Randomized phase III study comparing paclitaxel/cisplatin/gemcitabine and gemcitabine/cisplatin in patients with locally advanced or metastatic urothelial cancer without prior systemic therapy: EORTC Intergroup Study 30987. J Clin Oncol. 2012; 30(10): 1107-1113.

17. Bellmunt J, Orsola A, Leow JJ, et al. Bladder cancer: ESMO practice guidelines for diagnosis, treatment and follow-up. Ann Oncol. 2014; 25 (Suppl 3): iii40-8.

18. Galsky MD, Hahn NM, Rosenberg J, et al. Treatment of patients with metastatic urothelial cancer "unfit" for cisplatin-based chemotherapy. J Clin Oncol. 2011; 29(17): 2432-2438.

19. Sonpavde G, Galsky MD, Vogelzang NJ. First-line systemic therapy trials for advanced transitional-cell carcinoma of the urothelium: should we stop separating cisplatin-eligible and -ineligible patients? J Clin Oncol. 2010; 28(25e): 441-2; author reply e443-4.

20. Houede N, Locker G, Lucas C, et al. Epicure: a European epidemiological study of patients with an advanced or metastatic Urothelial Carcinoma (UC) having progressed to a platinum-based chemotherapy. BMC Cancer. 2016; 16(1): 752.

21. JAVLOR (vinflunine). [summary of product characteristics]. South San Francisco, CA: Genentech, Inc.; 2016. 
22. Bellmunt J, Theodore C, Demkov T, et al. Phase III trial of vinflunine plus best supportive care compared with best supportive care alone after a platinum-containing regimen in patients with advanced transitional cell carcinoma of the urothelial tract. J Clin Oncol. 2009; 27(27): 4454-4461.

23. Sonpavde G, Pond GR, Choueiri TK, et al. Single-agent taxane versus taxane-containing combination chemotherapy as salvage therapy for advanced urothelial carcinoma. Eur Urol. 2016; 69(4): 634-641.

24. [Internet] National Comprehensive Cancer Network. NCCN Clinical Practice Guidelines in Oncology: bladder cancer. V5.2017. 2017. https://www .nccn.org/professionals/physician_gls/pdf/bladder.pdf.

25. Bellmunt J, Choueiri TK, Fougeray R, et al. Prognostic factors in patients with advanced transitional cell carcinoma of the urothelial tract experiencing treatment failure with platinum-containing regimens. J Clin Oncol. 2010; 28(11): 1850-1855.

26. Bellmunt J, Mottet N, De Santis M. Urothelial carcinoma management in elderly or unfit patients. EJC Suppl. 2016; 14(1): 1-20.

27. Bamias A, Tzannis K, Harshman LC, et al. Impact of contemporary patterns of chemotherapy utilization on survival in patients with advanced cancer of the urinary tract: a retrospective international study of invasive/advanced cancer of the urothelium (RISC). Ann Oncol. 2017; [Epub ahead of print].

28. Choueiri TK, Ross RW, Jacobus S, et al. Double-blind, randomized trial of docetaxel plus vandetanib versus docetaxel plus placebo in platinum-pretreated metastatic urothelial cancer. J Clin Oncol. 2012; 30(5): 507-512.

29. Pal SK, Galsky MD, Lin S, et al. Second-line metastatic urothelial carcinoma treatment and survival in real-world patients in the United States. Ann Oncol. 2016; 27(6): 266-295.

30. Hegele A, Goebell P, Matz U, Neuhaus T. Monotherapy with intravenous vinflunine in patients with advanced or metastatic urothelial cancer after failure of a platinum-containing regimen: a retrospective analysis of German routine data. Urol Int. 2014; 92(2): 174-179.

31. Retz M, de Geeter P, Goebell PJ, Matz U, de Schultz W, Hegele A. Vinflunine in routine clinical practice for the treatment of advanced or metastatic urothelial cell carcinoma - data from a prospective, multicenter experience. BMC Cancer. 2015; 15: 455-460.

32. Garcia-Donas J, Font A, Perez-Valderrama B, et al. Maintenance therapy with vinflunine plus best supportive care versus best supportive care alone in patients with advanced urothelial carcinoma with a response after first-line chemotherapy (MAJA; SOGUG 2011/02): a multicentre, randomised, controlled, open-label, phase 2 trial. Lancet Oncol. 2017; 18(5): 672-681.

33. Medioni J, Di Palma M, Guillot A, Spaeth D, Theodore C. Efficacy and safety of vinflunine for advanced or metastatic urothelial carcinoma in routine practice based on the French multi-centre CURVE study. BMC Cancer. 2016; 16: $217-225$.

34. Castellano $D$, Puente $J$ de Velasco $G$, et al. Safety and effectiveness of vinflunine in patients with metastatic transitional cell carcinoma of the urothelial tract after failure of one platinum-based systemic therapy in clinical practice. BMC Cancer. 2014; 14: 779-287.

35. Bellmunt J, de Wit R, Vaughn DJ, et al. Pembrolizumab as second-line therapy for advanced urothelial carcinoma. N Engl J Med. 2017; 376(11): 1015-1026.

36. Powles T, Loriot $\mathrm{Y}$, Durán I, et al. IMvigor211: a phase III randomized study examining atezolizumab versus chemotherapy for platinum-treated advanced urothelial carcinoma. Presented at EACR-AACR-SIC Special Conference [abstract 606]. 2017; Florence, Italy.

37. Rosenberg JE, Hoffman-Censits J, Powles T, et al. Atezolizumab in patients with locally advanced and metastatic urothelial carcinoma who have progressed following treatment with platinum-based chemotherapy: a single-arm, multicentre, phase 2 trial. Lancet. 2016; 387(10031): 1909-1920.

38. Balar AV, Galsky MD, Rosenberg JE, et al. Atezolizumab as first-line treatment in cisplatin-ineligible patients with locally advanced and metastatic urothelial carcinoma: a single-arm, multicentre, phase 2 trial. Lancet. 2017; 389(10064): 67-76.

39. Sharma P, Retz M, Siefker-Radtke A, et al. Nivolumab in metastatic urothelial carcinoma after platinum therapy (CheckMate 275): a multicentre, single-arm, phase 2 trial. Lancet Oncol. 2017; 18(3): 312-322.

40. Apolo AB, Infante JR, Balmanoukian A, et al. Avelumab, an anti-programmed death-ligand 1 antibody, in patients with refractory metastatic urothelial carcinoma: results from a multicenter, phase Ib study. J Clin Oncol. 2017; 35: 2117-2124.

41. Massard C, Gordon MS, Sharma S, et al. Safety and efficacy of durvalumab (MEDI4736), an anti-programmed cell death ligand-1 immune checkpoint inhibitor, in patients with advanced urothelial bladder cancer. J Clin Oncol. 2016; 34(26): 3119-3125. 